\title{
Drug adherence to biologic DMARDS with a special emphasis on the benefits of subcutaneous abatacept
}

\author{
Anshuman P Malaviya' \\ Andrew JK Östör ${ }^{1,2}$ \\ 'Rheumatology Clinical Research \\ Unit, Addenbrooke's Hospital, \\ Cambridge, UK; ${ }^{2}$ School of Clinical \\ Medicine, University of Cambridge, \\ Cambridge, UK
}

This article was published in the following Dove Press journal:

Patient Preference and Adherence

14 August 2012

Number of times this article has been viewed

\begin{abstract}
Major advances in drug development have led to the introduction of biologic disease-modifying drugs for the treatment of rheumatoid arthritis, which has resulted in unprecedented improvement in outcomes for many patients. These agents have been found to be effective in reducing clinical signs and symptoms, improving radiological damage, quality of life, and functionality, and have also been found to have an acceptable safety profile. Despite this, drug adherence is unknown, which has huge health care and health-economic implications. Local and national guidelines exist for the use of biologics; however, its varied use is widespread. Although this may in part reflect differences in prescribing behavior, patient preference plays a key role. In this review we will explore the factors that contribute to patient preference for, and adherence to, biologic therapy for rheumatoid arthritis with emphasis on the subcutaneous preparation of abatacept, a T-cell costimulatory molecule blocker. Overall, subcutaneous administration is preferred by patients and this may well improve drug adherence.
\end{abstract}

Keywords: subcutaneous administration, self-injectable, abatacept, rheumatoid arthritis, preference, adherence, compliance, biologic DMARD

\section{Introduction}

Over the last 15 years, a transformation in the therapeutic landscape of rheumatoid arthritis (RA) has been seen with a number of highly efficacious drugs having become available. The expense of drug development coupled with a restricted market has influenced the cost of these medications, with the average biologic disease-modifying antirheumatic drug (bDMARD) costing around $£ 10,000$ per annum in the United Kingdom. It is therefore essential that these newer therapies are acceptable to patients, and that adherence is maintained. In light of this, there has been considerable interest in determining the factors that contribute to both patient preference for and adherence to medications.

The complex and poorly understood field of drug adherence represents an enormous health care challenge. The World Health Organization suggests that $<50 \%$ of patients with chronic illness take their therapies as prescribed, and up to $30 \%$ of prescriptions in the United States are never filled. ${ }^{1,2}$ Nonadherence to medication is associated with greater morbidity and mortality in chronic diseases. ${ }^{3-5}$ Furthermore, nonadherence has been found to be quite costly to health care, with estimates suggesting an additional $\$ 170$ billion annually in the US has been spent as a consequence of nonadherence. ${ }^{6}$ Patient adherence to bDMARDs is difficult to evaluate, and the results from studies that have explored this area are unclear. In Crohn's disease, for instance, nonadherence to intravenous infliximab maintenance therapy has been estimated to be $34 \%$ in 
the first year. ${ }^{7}$ Given that infliximab is administered as an 8-weekly intravenous infusion (compared with etanercept and adalimumab, which are weekly and fortnightly subcutaneous injections, respectively), it appears that adherence does not appear to be much better for intravenous therapy than other modes of administration.

In light of this, we undertook a review to explore adherence to bDMARDs in patients with RA. Since the terms "compliance," "adherence," "concordance," and "persistence" are often used interchangeably, we have restricted our discussion to adherence (see Table 1 for definitions of terms), while taking into account the factors influencing preference for biologic therapies in patients with RA. In addition, we have summarized the trial evidence for abatacept use in RA, and have highlighted the potential advantages of a self-injectable, subcutaneous (SC) form of the drug.

\section{Pharmacotherapy for RA Adherence to treatment in rheumatoid arthritis}

A number of critical issues appear to influence patient adherence to therapies. These include patient- and physician-specific factors as well as treatment-associated factors (Figure 1). "Self-efficacy" (defined as an individual's belief that current health behaviors will impact future health) appears to play an important role. ${ }^{9}$ Social support, level of education, and age also contribute to adherence. ${ }^{8-10}$ Furthermore, drug tolerability appears to affect adherence to pharmacotherapy. For example, many conventional DMARDs are deemed to be well-tolerated; however, data exists to the contrary. Gispen et al ${ }^{11}$ provided follow-up

Table I Definitions of adherence, compliance, concordance, and persistence

\begin{tabular}{ll}
\hline Term & Definition \\
\hline I. Compliance & $\begin{array}{l}\text { The extent to which the patient's behavior matches } \\
\text { the prescriber's recommendations. There is an } \\
\text { implied lack of patient involvement. }\end{array}$ \\
2. Adherence & $\begin{array}{l}\text { The extent to which the patient continues the } \\
\text { agreed-upon mode of treatment under limited } \\
\text { supervision when faced with conflicting demands. }\end{array}$ \\
3. Concordance & $\begin{array}{l}\text { Encompasses the process in which doctor and } \\
\text { patient agree therapeutic decisions that incorporate } \\
\text { their respective views, to a wider concept which } \\
\text { stretches from prescribing communication to }\end{array}$ \\
& $\begin{array}{l}\text { patient support in medicine taking. } \\
\text { This refers to the duration of time that the patient } \\
\text { continues a specified therapy and may or may not } \\
\text { have conformed to the dosing schedule during } \\
\text { that time. }\end{array}$ \\
\hline
\end{tabular}

after 1 year for 72 patients with RA who were receiving oral methotrexate. They described that minor side-effects (oral ulcers, transient elevation of liver enzymes, and nausea) were seen in $64 \%$ of patients. Despite the importance of this, more recent data on the subject is lacking.

Adherence to biologic therapy is poorly understood since most studies have investigated drug persistence, which represents only a surrogate of adherence. It has been found that persistence with anti-TNF (tumor necrosis factor) therapy varies from $20 \%$ at 36 months for infliximab to $89 \%$ at 6 months for unselected TNF antagonists. ${ }^{8}$ The reasons for this are multifactorial, and include primary and secondary inefficacy, as well as degree of tolerability. It should be noted that persistence data from prospective clinical trials is inherently biased and does not necessarily reflect real-life experience. Studies have also used medication possession ratio and administrative claims data to measure adherence. For instance, the Danish biologics registry (DANBIO), which is following patients who are taking infliximab, adalimumab, and etanercept, suggests that patients receiving infliximab had the lowest rates of drug adherence, although the methods used to assess this were not specified. ${ }^{12}$ A further study by Li et $\mathrm{al}^{13}$ which looked at drug switching, discontinuation, and adherence in Medicaid patients with RA after 12 months of biologic therapy, used "proportion of days covered" (PDC) as a measure of adherence. Those patients receiving anakinra (an IL-1 receptor antagonist) were found to be the least adherent (PDC 0.36), whereas infliximab users were the most adherent (PDC 0.64). Harley et $\mathrm{al}^{14}$ found compliance to be higher in patients receiving infliximab when compared with etanercept. A further study exploring patients who were prescribed adalimumab and etanercept demonstrated a marked reduction in drug adherence, which was associated with higher out-of-pocket costs. ${ }^{15}$ Although this may be a critical issue in certain parts of the world, out-of-pocket expenses are less relevant in the UK. Despite this, adherence to biologic therapy is far from ideal and is affected by a number of factors, some of which have yet to be defined.

\section{Preference for biologic therapy in rheumatoid arthritis}

With an array of different bDMARDs having similar efficacy and tolerability, patient preference is of major importance in the treatment decision. In one study focusing on preference for anti-TNF therapy, most patients preferred the subcutaneous mode of administration over intravenous and intramuscular administration ( $41 \%$ of patients on antiTNF drugs and $56 \%$ of those not on anti-TNFs preferred 


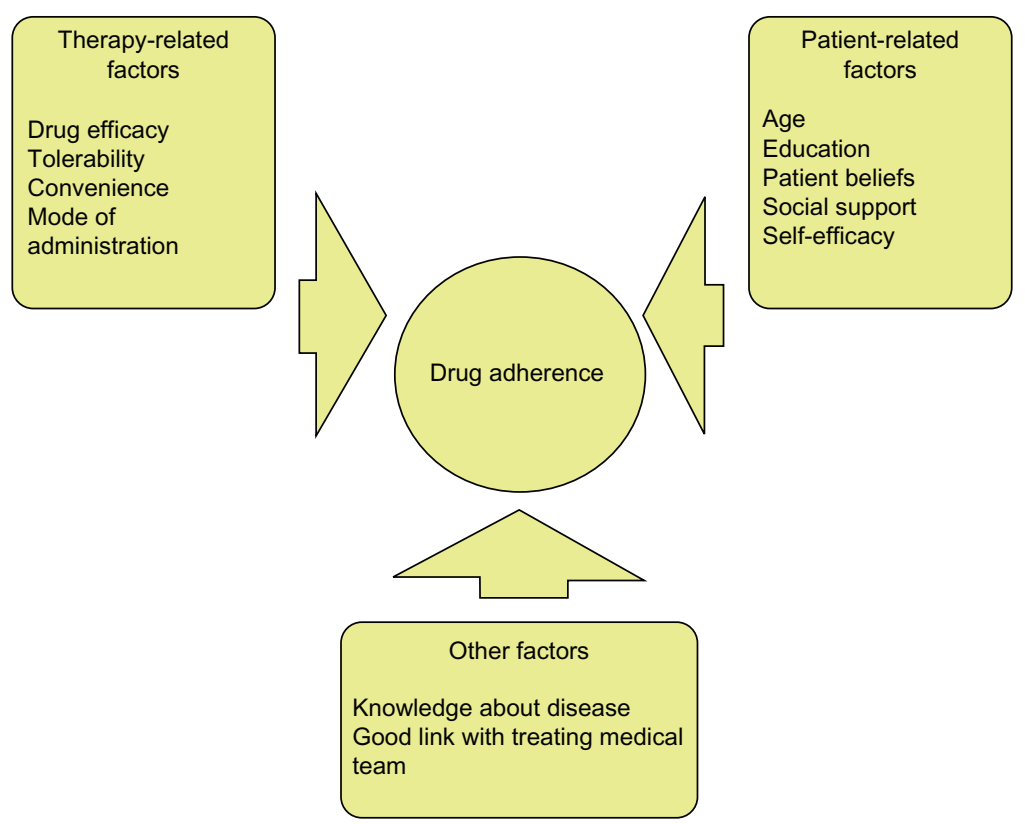

Figure I Factors that influence adherence to treatment in patients with rheumatoid arthritis.

subcutaneous administration over intravenous and intramuscular injections). ${ }^{16}$ The majority of individuals $(62.5 \%$ of those on anti-TNF treatment and $52 \%$ not yet on anti-TNF therapy) also preferred treatment administration at home rather than in hospital. In another study exploring patient preference for anti-TNF therapy, more than $75 \%$ of patients preferred subcutaneous over intravenous administration. ${ }^{17}$ Furthermore, over three-quarters of the patients preferred a self-administered prefilled syringe over a drug requiring reconstitution administered intravenously every 8 weeks. Acceptance of SC auto-injector drug delivery has also been studied and compared with traditional SC injections. It has been found that individuals universally prefer the autoinjector. ${ }^{18}$ This mode of administration may have the additional advantage of ease of use in patients with RA-associated hand deformities.

Patient preference on who should make the decision about biologic therapy has been explored in one study. ${ }^{19}$ Interestingly, the majority of patients (43\%) felt that the rheumatologist should decide, while $7 \%$ felt it should be a joint decision. A total of 33\% felt the patient should decide, and $19 \%$ were undecided. When given a choice of adalimumab, etanercept, and infliximab, the majority of patients preferred adalimumab (licensed for SC treatment every 2 weeks) with patients younger than 61 years preferring SC over intravenous (IV) therapy. ${ }^{19}$ Finally, the merits of both subcutaneous and intravenous therapy have been investigated in relation to re-imbursement (Medicare patients in the US may only claim costs for drugs that cannot be self-administered). ${ }^{20}$
This diversity in attitudes towards and influences affecting treatment preference and adherence further indicates that no single factor universally affects patient preference.

\section{T-lymphocyte costimulation blockade with abatacept}

Abatacept (Orencia Bristol Myers Squibb) is a novel bDMARD licensed for use in the treatment of RA and juvenile idiopathic arthritis. It is a costimulatory molecule blocker which inhibits the activation of T-cells. Abatacept consists of an Fc portion of immunoglobulin, which is attached to the extra-cellular domain of cytotoxic T-lymphocyte antigen-4 (Figure 2). Activation of T-cells requires binding of the T-cell receptor to the antigen-major histocompatibility complex on the antigen-presenting cell (APC) and costimulation including CD28 (on the T-cell) binding to $\mathrm{CD} 80 / 86$ on the APC. Abatacept has a high affinity for CD80/86 and thus inhibits T cell co-stimulation and activation. Abatacept is administered intravenously $(10 \mathrm{mg} / \mathrm{kg})$ monthly after initial loading; however, a subcutaneous preparation (125 mg weekly after an initial intravenous loading dose) has also been approved by the Food and Drug Administration for moderate to severe RA.

\section{Efficacy of intravenous abatacept}

A number of Phase 3 randomized controlled trials have been undertaken with abatacept. These include AIM (Abatacept in Inadequate responders to Methotrexate); ${ }^{21}$ ATTAIN (Abatacept Trial in Treatment of Anti-TNF 


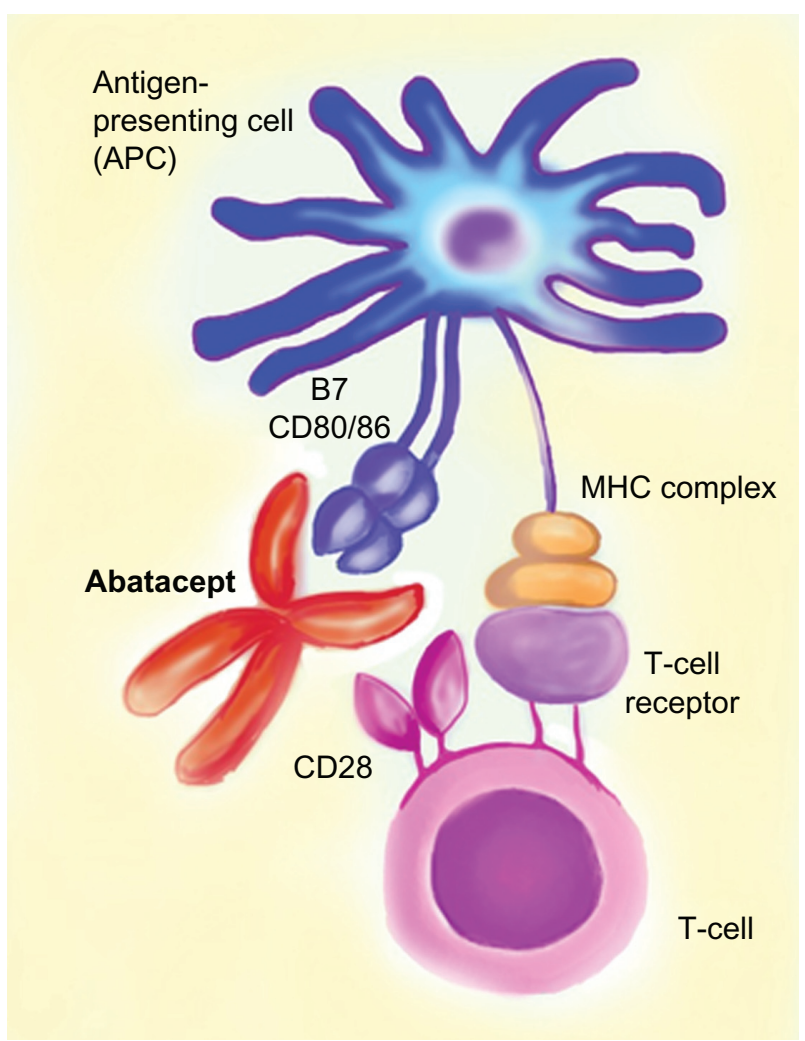

Figure 2 Illustration describing the mechanism of action of abatacept. Abatacept has high affinity for CD80/86 on the APC and prevents binding of this molecule with CD28 on the T-cell, thus ultimately preventing T-cell costimulation.

Note: MHC complex refers to the major histocompatibility complex (MHC) molecule presenting the antigen to the T-cell receptor.

INadequate responders); ${ }^{22}$ ATTEST (A Trial for Tolerability, Efficacy, and Safety in Treating RA); ${ }^{23}$ AGREE (Abatacept study to Gauge Remission and joint damage progression in MTX [methotrexate]-naïve patients with Early Erosive RA) ${ }^{24}$ and ASSURE (Abatacept Study of Safety in Use with other Rheumatoid Arthritis therapies). ${ }^{25}$ In addition, a Phase 2 study known as ADJUST (Abatacept study to Determine the effectiveness in preventing the development of RA in patients with Undifferentiated inflammatory arthritis and to evaluate Safety and Tolerability ${ }^{26}$ has been investigating the effects of abatacept on early undifferentiated anti-cyclic citrullinated protein antibody-positive inflammatory arthritis.

The AIM study sought to evaluate the safety and efficacy of abatacept in patients with RA that had previously failed MTX treatment. ${ }^{21}$ The study also included radiological outcomes as a primary end point. Statistically significant American College of Rheumatology (ACR) 20, 50, and 70 response rates were seen at 6 months and 1 year compared to the placebo arm. $73.1 \%$ of patients in the abatacept arm achieved an ACR20 response when compared to $39.7 \%$ of patients in the placebo arm at 12 months $(P<0.001)$.
Radiological outcomes also improved in the active arm and were sustained over the course of long-term treatment.

ATTAIN was a randomized, placebo-controlled trial aimed at assessing the efficacy and tolerability of abatacept in patients who had an inadequate response to anti-TNF therapy. ${ }^{22}$ Patients were randomized to receive abatacept or placebo in addition to bDMARD therapy. At 6 months, the ACR20 response rates were $50 \%$ in the abatacept-treated group when compared to $19.5 \%$ in the placebo group $(P<0.001)$. Patients who received treatment demonstrated statistically significant response rates when compared to the placebo group at 6 months.

The ATTEST study was a comparator trial with three arms - abatacept, infliximab, or placebo - on a background of MTX. ${ }^{23}$ The trial, however, was not powered to distinguish between the effects of abatacept and infliximab on RA outcomes. Both active arms demonstrated statistically significant improvement in ACR response rates when compared to placebo, and, interestingly, the response rates appeared to be consistently higher for abatacept than for infliximab.

The ADJUST study was designed to determine the effects of abatacept in early undifferentiated arthritis or very early rheumatoid arthritis. ${ }^{26} 50$ patients were recruited to this Phase 2 study and were randomized to receive either abatacept or placebo for 6 months. The primary end point was the development of RA at 12 months. Fewer patients in the abatacept group (12/26 or $46 \%)$ progressed to RA when compared with the placebo group (16/24 or $67 \%$ ). However, the difference between the two groups did not achieve statistical significance. Similar improvements in the active group were seen in modified Sharp scores and magnetic resonance imaging erosion scores, but again these results did not achieve statistical significance.

Finally, the AGREE study was a multinational, randomized, placebo-controlled trial comparing the efficacy of the combination of abatacept and methotrexate in patients who were methotrexate naïve. ${ }^{24}$ The primary end point was a disease activity score of 28 and remission at 12 months. $41 \%$ of patients achieved this end point when compared to $23 \%$ of controls $(P<0.001)$. Statistically significant differences were also noted in the proportion of patients achieving ACR50 and ACR70, and in radiological outcomes in the active arm.

\section{Efficacy of subcutaneous abatacept in RA}

The efficacy and safety of SC abatacept has been trialed in two Phase 3B randomized controlled trials (ACQUIRE ${ }^{27}$ [Abatacept Comparison of $\mathrm{Sub}(\mathrm{QU})$ cutaneous versus Intravenous in inadequate Responders to methotrexate] and ALLOW [evaluation of Abatacept administered subcutaneousLy in AduLts 
with active rheumatOid arthritis: impact of Withdrawal and reintroduction on immunogenicity, efficacy and safety $]^{28}$ ) and two Phase 3B open-labeled studies (ATTUNE ${ }^{29}$ and ACCOMPANY ${ }^{30}$ ). ACQUIRE was a Phase 3 noninferiority study comparing the safety and efficacy of SC abatacept with the IV formulation over 6 months. The ACR and disease activity score remission responses are outlined in Table 2 . No significant differences were seen in the two groups, with ACR20 response rates of $76 \%$ in the SC group and $75.8 \%$ in the IV group. The trial has revealed that SC abatacept demonstrates comparable efficacy to the IV formulation and also has a high retention rate.

Another Phase 3B trial (ALLOW) studied the effects of temporary cessation of SC abatacept on immunogenicity, side-effects, and efficacy. Drug withdrawal for 3 months followed by reintroduction was not associated with increased immunogenicity, and no safety or efficacy concerns were identified.

The ACCOMPANY study ${ }^{30}$ looked at the safety and efficacy of SC abatacept without an IV loading dose. At 12 weeks no statistically significant differences were seen, suggesting that the IV loading may not be an absolute prerequisite.

\section{Safety and tolerability of abatacept in RA}

In a pooled analysis of a number of randomized controlled trials using abatacept (4764 patient-years of exposure), the rate of adverse events, serious adverse events, and malignancy rates were no different between the abatacept and the placebo-treated groups. ${ }^{31}$ To date, no flags have been raised in relation to abatacept's association or impact on heart failure and malignancy. ${ }^{31}$ In addition, the immunogenecity of IV abatacept in the pooled analysis was not found to be associated with loss of efficacy or adverse events. ${ }^{21}$ Literature suggests that the likelihood of an immune response to a biologic agent is greater after SC administration than after an IV infusion..$^{32}$ Data from the ALLOW study demonstrated that SC abatacept was not more immunogenic than the IV preparation. ${ }^{28}$ Injection-site reactions were reported among two patients in the initial phase of the study. The reactions were mild and did not appear to recur when the drug was reintroduced later in the study.

Long-term extension data from one trial has demonstrated acceptable patient tolerability and efficacy of abatacept lasting up to 5 years..$^{33}$ Infusion reactions in the IV abatacept studies have been seen in $9 \%$ of actively treated patients when compared with $6 \%$ of controls; however, overall these

Table 2 Key clinical trial data for intravenous and subcutaneous abatacept in the treatment of RA

\begin{tabular}{|c|c|c|c|c|c|c|c|}
\hline \multirow{2}{*}{$\begin{array}{l}\text { Study name } \\
\text { (study duration) }\end{array}$} & \multirow{2}{*}{ Key features } & \multirow[t]{2}{*}{$\mathbf{n}$} & \multicolumn{5}{|l|}{ Results* } \\
\hline & & & $\begin{array}{l}\text { ACR } 20 \\
\text { (control arm) }\end{array}$ & $\begin{array}{l}\text { ACR } 50 \\
\text { (control arm) }\end{array}$ & $\begin{array}{l}\text { ACR } 70 \\
\text { (control arm) }\end{array}$ & $\begin{array}{l}\text { DAS } 28 \\
\text { remission } \\
\text { (control arm) }\end{array}$ & $\begin{array}{l}\text { Improved } \\
\text { radiological } \\
\text { outcomes }\end{array}$ \\
\hline \multicolumn{8}{|c|}{ Studies with intravenous abatacept } \\
\hline $\begin{array}{l}\text { AIM' } \\
\text { (I2 months) } \\
\text { Kremer et al }\end{array}$ & $\begin{array}{l}A B T+M T X \text { versus MTX } \\
\text { alone in MTX-inadequate } \\
\text { responders }\end{array}$ & 652 & $73(40)$ & $48(18)$ & $29(6)$ & NA & Yes \\
\hline $\begin{array}{l}\text { ATTEST }^{2} \\
\text { (12 months) }\end{array}$ & $\begin{array}{l}\text { MTX failure: abatacept or } \\
\text { infliximab active arms }\end{array}$ & 431 & $72(56)^{\ddagger}$ & $46(36)^{\ddagger}$ & $26(21)^{\ddagger}$ & $19(12)^{\ddagger}$ & Not assessed \\
\hline \multicolumn{8}{|l|}{ Schiff et al } \\
\hline $\begin{array}{l}\text { (6 months) } \\
\text { Genovese et al }\end{array}$ & $\begin{array}{l}\text { MTX alone in anti-TNF } \\
\text { inadequate responders }\end{array}$ & דונד & Ju (20) & $20(T)$ & $10(2)$ & 的 & Tur assessed \\
\hline $\begin{array}{l}\text { AGREE } \\
\text { (12 months) }\end{array}$ & $\begin{array}{l}A B T+M T X \text { in MTX- } \\
\text { naïve patients with RA }\end{array}$ & 509 & - & $57(42)$ & $43(27)$ & $4 \mid(23)$ & Yes \\
\hline $\begin{array}{l}\text { ADJUST }^{4} \\
\text { (Phase 2- } \\
6 \text { months) }\end{array}$ & $\begin{array}{l}A B T \text { versus placebo in } \\
\text { early undifferentiated } \\
\text { anti-CCP positive arthritis }\end{array}$ & 50 & - & - & - & $67(46)$ & Yes \\
\hline \multicolumn{8}{|c|}{ Studies with subcutaneous abatacept } \\
\hline $\begin{array}{l}\text { ACQUIRE }^{5} \\
\text { (6 months) } \\
\text { Genovese et al }\end{array}$ & $S C A B T$ versus IV $A B T$ & 1457 & $76(75.8)^{*}$ & $50(49)^{*}$ & $26(24)^{*}$ & $24(25)^{*}$ & Not assessed \\
\hline
\end{tabular}

Notes: ${ }^{*}$ The control arm shows the response rates with infliximab. The response rates for the placebo arm are not shown; ${ }^{*}$ Noninferiority study with IV ABT as the control arm. Figures represent the percentages of patients achieving ACR/DAS responses in the intention-to-treat population.

Abbreviations: $n$, number; ACR, American College of Rheumatology; DAS, disease activity score; ABT, abatacept; MTX, methotrexate; TNF, tumor necrosis factor; RA, rheumatoid arthritis; CCP, anti-cyclic citrullinated protein antibody; SC, subcutaneous; IV, intravenous. 
effects were mild. ${ }^{24}$ Combined data from five RCTs has suggested that the risk of serious infections is 3\% compared to $1.9 \%$ in the placebo groups. ${ }^{34}$ Interestingly, a Cochrane safety review suggested that abatacept had a better safety profile than most other biologics. ${ }^{35}$ This data pertains to IV abatacept; however, it is reassuring that data from the SC abatacept studies ${ }^{27,28}$ indicates that SC abatacept is at least as safe as IV abatacept.

\section{Pharmacoeconomics}

Although clinical effectiveness (quality, efficacy, and tolerability) of any new pharmacotherapy is paramount, it is increasingly necessary that cost-effectiveness is demonstrated as well. This is particularly relevant to biologic therapy in RA, where a number of drugs are available. Cost of therapy is even more important when treatment is privately funded. Cost-effectiveness is affected by a number of factors, not least of which is drug adherence. A study looking at the cost-effectiveness of osteoporosis therapy concluded that the cost per quality-adjusted life year increased from $€ 4871$ (assuming full compliance and medicine possession ratio of $100 \%$ ) to $€ 30,181$ if compliance (measured by medicine possession ratio) fell to $60 \%{ }^{36}$ This clearly demonstrates the impact of drug adherence on cost-effectiveness and drugs that can demonstrate higher adherence are likely to be more cost-effective.

The need for monthly infusions and the resulting higher relative cost of IV abatacept has limited its use in the UK to patients with RA who have failed (or not tolerated) antiTNFs and rituximab. ${ }^{37}$ Introduction of SC abatacept will certainly impact upon its cost-effectiveness both by negating the need for infusions and by promoting potentially higher adherence. As a result, it is likely that, in the future, the UK National Institute for Health and Clinical Excellence will rule in favor of earlier use of SC abatacept.

\section{"Oral" biologics}

Recently there has been considerable interest in oral "small molecules" that bind to specific intracellular receptors thereby influencing the proinflammatory cascade. A number of molecules have been studied in Phase 2 and 3 clinical trials. Some of these newer drugs have demonstrated levels of efficacy that are comparable to anti-TNF therapies. A recent Phase 2B study comparing the efficacy of tofacitinib (an inhibitor of Janus kinase-3 enzyme which interferes with the JAK-STAT intra-cellular signaling pathway) with adalimumab demonstrated similar efficacy of the two drugs when used as monotherapy. ${ }^{38}$ Fostimatinib, a spleen tyrosine kinase inhibitor, showed promise in initial trials; however, recent reports suggest that it may be no more effective than placebo in patients who have previously failed biologic therapy. ${ }^{39}$ Mitogen-activated protein kinase inhibitors are another promising group of drugs. However, current data from human studies have demonstrated a potentially unacceptable side-effect profile with hepatotoxicity and gastrointestinal side-effects. ${ }^{40}$ While these effects are almost certainly more acceptable to patients than parenteral therapy, the true role of these oral 'biologics' in the treatment of RA remains to be seen.

\section{Conclusion}

Although the search for the optimal therapy for RA continues, parenteral administration is unlikely to diminish in the short to medium term. bDMARDs such as abatacept, with well-established efficacy, safety, and tolerability will continue to form an integral part of the treatment paradigm. The SC, self-injectable form of abatacept is effective and well-tolerated and is certainly a welcome addition to the therapeutic armamentarium for RA. In our opinion, it will be well-received by patients, thereby improving adherence and treatment outcomes for patients living with this previously crippling disease.

\section{Disclosure}

Dr Malaviya's clinical research fellowship is funded by CARE (Cambridge Arthritis Research Endeavour). Andrew Östör has received support from, attended conferences by, undertakes clinical trials with, and acts as a consultant to Roche, Chugai, MSD, Abbott, Pfizer, BMS, GSK, MerckSorono, and UCB.

\section{References}

1. World Health Organization. Adherence to Long-Term Therapies: Evidence for Action. Geneva: World Health Organization; 2003. Available from: http:// apps.who.int/medicinedocs/en/d/Js4883e/. Accessed 19 June, 2012.

2. Fischer MA, Stedman MR, Lii J, et al. Primary medication nonadherence: analysis of 195,930 electronic prescriptions. J Gen Intern Med. Apr 2010;25(4):284-290.

3. Ho PM, Rumsfeld JS, Masoudi FA, et al. Effect of medication nonadherence on hospitalization and mortality among patients with diabetes mellitus. Arch Intern Med. 2006;166:1836-1841.

4. Ho PM, Spertus JA, Masoudi FA, et al. Impact of medication therapy discontinuation on mortality after myocardial infarction. Arch Intern Med. 2006;166:1842-1847.

5. Sokol MC, McGuigan KA, Verbrugge RR, Epstein RS. Impact of medication adherence on hospitalization risk and healthcare cost. Med Care. 2005;43:521-530.

6. Caro JJ, Salas M, Speckman JL, Raggio G, Jackson JD. Persistence with treatment for hypertension in actual practice. CMAJ. 1999;160(1): 31-37.

7. Kane SV, Chao J, Mulani PM. Adherence to infliximab maintenance therapy and health care utilization and costs by Crohn's disease patients. Adv Ther. 2009;26(10):936-946. 
8. Salt E, Frazier S. Adherence to disease-modifying antirheumatic drugs in rheumatoid arthritis in patients with rheumatoid arthritis: a narrative review of the literature. Orthop Nurs. 2010;29(4):260-275.

9. de Klerk E, van der Heijde D, Landewé R, van der Tempel H, Urquhart J, van der Linden S. Patient compliance in rheumatoid arthritis, polymyalgia rheumatica, and gout. J Rheumatol. 2003;30(1):44-54.

10. Park DC, Hertzog C, Leventhal H, et al. Medication adherence in rheumatoid arthritis patients: older is wiser. JAm Geriatr Soc. 1999;47(2): 172-183.

11. Gispen JG, Alarcón GS, Johnson JJ, Acton RT, Barger BO, Koopman WJ. Toxicity of methotrexate in rheumatoid arthritis. J Rheumatol. 1987;14(1):74-79.

12. Hetland ML, Christensen IJ, Tarp U, et al. Direct comparison of treatment responses, remission rates, and drug adherence in patients with rheumatoid arthritis treated with adalimumab, etanercept, or infliximab: results from eight years of surveillance of clinical practice in the nationwide Danish DANBIO registry. Arthritis Rheum. 2010;62:22-32.

13. Li P, Blum MA, Von J, Hennessy S, Doshi JA. Adherence, discontinuation, and switching of biologic therapies in medicaid enrollees with rheumatoid arthritis. Value Health. 2010;13(6):805-812.

14. Harley C, Frytak J, Tandon N. Treatment compliance and dosage administration among rheumatoid arthritis patients receiving infliximab, etanercept, or methotrexate. Am J Manag Care. 2003;9(Suppl 6):S136-S143.

15. Curkendall S, Patel V, Gleeson M, Campbell RS, Zagari M, Dubois R. Compliance with biologic therapies for rheumatoid arthritis: do patient out-of-pocket payments matter? Arthritis Rheum. 2008;59: 1519-1526.

16. Williams EL, Edwards CJ. Patient preferences in choosing anti-TNF therapies-R1. Rheumatology (Oxford). 2006;45(12):1575-1576.

17. Jeffery M, Stokes A, Johnson K, Anderson D, Harper B. Patient Preferences for Tumor Necrosis Factor (TNF) Antagonist. London, UK and Dallas, TX: The Research Partnership Ltd, Rheumatology Research International; 2004.

18. Berteau C, Schwarzenbach F, Donazzolo Y, et al. Evaluation of performance, safety, subject acceptance, and compliance of a disposable autoinjector for subcutaneous injections in healthy volunteers. Patient Prefer Adherence. 2010;4:379-388.

19. Chilton F, Collett RA. Treatment choices, preferences and decisionmaking by patients with rheumatoid arthritis. Musculoskeletal Care. 2008;6(1):1-14.

20. Schwartzman S, Morgan GJ Jr. Does route of administration affect the outcome of TNF antagonist therapy? Arthritis Res Ther. 2004; 6 Suppl 2:S19-S23.

21. Kremer JM, Genant HK, Moreland LW, et al. Effects of abatacept in patients with methotrexate-resistant active rheumatoid arthritis: a randomized trial. Ann Intern Med. 2006;144(12):865-876.

22. Genovese MC, Becker JC, Schiff M, et al. Abatacept for rheumatoid arthritis refractory to tumor necrosis factor alpha inhibition. $N$ Engl J Med. 2005;353:1114-1123.

23. Schiff M, Keiserman M, Codding C, et al. Efficacy and safety of abatacept or infliximab vs placebo in ATTEST: a phase III, multi-centre, randomised, double-blind, placebo-controlled study in patients with rheumatoid arthritis and an inadequate response to methotrexate. Ann Rheum Dis. 2008;67:1096-1103.

24. Westhovens R, Robles M, Ximenes AC, et al. Clinical efficacy and safety of abatacept in methotrexate-naive patients with early rheumatoid arthritis and poor prognostic factors. Ann Rheum Dis. 2009;68(12): $1870-1877$.

25. Weinblatt M, Combe B, Covucci A, Aranda R, Becker JC, Keystone E. Safety of the selective costimulation modulator abatacept in rheumatoid arthritis patients receiving background biologic and nonbiologic disease-modifying antirheumatic drugs: a one-year randomized, placebo-controlled study. Arthritis Rheum. 2006;54: 2807-2816.
26. Emery P, Durez P, Dougados M, et al. Impact of T-cell costimulation modulation in patients with undifferentiated inflammatory arthritis or very early rheumatoid arthritis: a clinical and imaging study of abatacept (the ADJUST trial). Ann Rheum Dis. 2010;69:510-516.

27. Genovese MC, Covarrubias A, Leon G, et al. Subcutaneous abatacept versus intravenous abatacept: a phase IIIb noninferiority study in patients with an inadequate response to methotrexate. Arthritis Rheum. 2011;63(10):2854-2864.

28. Kaine J, Gladstein G, Strusberg I, et al. Evaluation of abatacept administered subcutaneously in adults with active rheumatoid arthritis: impact of withdrawal and reintroduction on immunogenicity, efficacy and safety (phase Iiib ALLOW study). Ann Rheum Dis. 2012; 71:38-44.

29. Keystone EC, Kremer JM, Russell A, et al. Abatacept in subjects who switch from intravenous to subcutaneous therapy: results from the phase IIIb ATTUNE study. Ann Rheum Dis. 2012;71(6):857-861.

30. Nash PT, Ludivico CL, Delaet I, et al. Efficacy, safety and pharmacokinetics of subcutaneous abatacept in patients with rheumatoid arthritis, with or without an intravenous (IV) loading dose [abstract]. Arthritis Rheum. 2011;63(Suppl 10):S151.

31. Sibilia J, Westhovens R. Safety of T-cell co-stimulation modulation with abatacept in patients with rheumatoid arthritis. Clin Exp Rheumatol. 2007;25(5 Suppl 46):S46-S56.

32. Porter S. Human immune response to recombinant human proteins. J Pharm Sci. 2001;90:1-11.

33. Westhovens R, Kremer JM, Moreland LW, et al. Safety and efficacy of the selective costimulation modulator abatacept in patients with rheumatoid arthritis receiving background methotrexate: a 5-year extended phase IIB study. J Rheumatol. Apr 2009;36(4):736-742.

34. Weinblatt M, Schiff M, Goldman A, et al. Selective costimulation modulation using abatacept in patients with active rheumatoid arthritis while receiving etanercept: a randomised clinical trial. Ann Rheum Dis. 2007;66:228-234.

35. Singh JA, Wells GA, Christensen R, et al. Adverse effects of biologics: a network meta-analysis and Cochrane overview. Cochrane Database Syst Rev. 2011;2:CD008794.

36. Hiligsmann M, Rabenda V, Gathon H-J, Ethgen O, Reginster J-Y. Potential clinical and economic impact of nonadherence with osteoporosis medications. Calcif Tissue Int. 2010;86(3):202-210.

37. National Institute for Health and Clinical Excellence (NICE). Adalimumab, Etanercept, Infliximab, Rituximab and Abatacept for the Treatment of Rheumatoid Arthritis after the Failure of a TNF Inhibitor. London, UK: National Institute for Health and Clinical Excellence; Aug 2010. 73 p. (Technology appraisal guidance; no. 195).

38. Fleischmann R, Cutolo M, Genovese MC, et al. Phase IIb dose ranging study of the oral JAK inhibitor tofacitinib (CP 690,550) or adalimumab monotherapy versus placebo in patients with active rheumatoid arthritis with an inadequate response to disease modifying antirheumatic drugs. Arthritis Rheum. 2012;64(3):617-629.

39. Genovese MC, Kavanaugh A, Weinblatt ME, et al. An oral Syk kinase inhibitor in the treatment of rheumatoid arthritis: a three-month randomized, placebo-controlled, phase II study in patients with active rheumatoid arthritis that did not respond to biologic agents. Arthritis Rheum. 2011;63:337-345.

40. Sweeney SE, Firestein GS. Mitogen activated protein kinase inhibitors: where are we now and where are we going? Ann Rheum Dis. 2006; (65 Suppl 3):iii83-iii88 


\section{Publish your work in this journal}

Patient Preference and Adherence is an international, peer-reviewed, open access journal focusing on the growing importance of patient preference and adherence throughout the therapeutic continuum. Patient satisfaction, acceptability, quality of life, compliance, persistence and their role in developing new therapeutic modalities and compounds to

optimize clinical outcomes for existing disease states are major areas of interest. This journal has been accepted for indexing on PubMed Central. The manuscript management system is completely online and includes a very quick and fair peer-review system. Visit http://www.dovepress.com/ testimonials.php to read real quotes from published authors.

Submit your manuscript here: http://www.dovepress.com/patient-preference-and-adherence-journal 